\title{
RARE EARTH DOPED NANOPARTICLES IN ORGANIC AND INORGANIC HOST MATERIALS FOR APPLICATION IN INTEGRATED OPTICS.
}

\author{
R. Dekker ${ }^{1)}$, L.T.H. Hilderink ${ }^{1)}$, M.B.J. Diemeer ${ }^{1)}$, \\ J.W. Stouwdam ${ }^{2)}$, V. Sudarsan ${ }^{2}$ ), F.C.J.M. van Veggel ${ }^{2)}$, K. Wörhoff ${ }^{1)}$, \\ and A. Driessen ${ }^{1)}$. \\ ${ }^{1)}$ University of Twente, Faculty of Electrical Engineering, Mathematics and Computer \\ Science, P.O.Box 217, 7500 AE Enschede, The Netherlands. Phone: +31-53-489 4440; \\ E-mail: R.Dekker@utwente.nl. \\ ${ }^{2)}$ University of Victoria, Department of Chemistry, P.O. Box 3065, Victoria, BC Canada \\ V8W 3 V6.
}

The preparation and the optical properties of lanthanum fluoride $\left(\mathrm{LaF}_{3}\right)$ nanoparticles doped with erbium and neodymium will be discussed. Organic and inorganic materials in the form of polymers and sol-gels were used to serve as the hosts for the inorganic nanoparticles, respectively. The organic host material has been synthesized such that it is photo-crosslinkable to facilitate straightforward multimode and monomode waveguide fabrication. Our focus will be on the optical properties of both the inorganic rare-earth doped nanoparticles and the host materials. The importance of the refractive indices of the particles and the host material and particle size on the optical scattering properties will be addressed. The optical transmission windows of the host materials do overlap with the absorption peaks of the erbium and neodymium in order to have efficient optical pumping, as well as with the spontaneous emission spectra of the rare earth metals for use as optical amplifiers around $1330 \mathrm{~nm}$ and $1550 \mathrm{~nm}$. Furthermore, the improvement on the excited state lifetimes of the rare earths in the nanoparticles compared to the lifetimes of rare earths directly immersed in sol-gels will be presented.

\section{INTRODUCTION}

The active optical properties of the rare earth ions erbium and neodymium are used to amplify the optical signals used in telecommunication systems around $1550 \mathrm{~nm}$ (1) and $1330 \mathrm{~nm}$, respectively. This amplification takes place through a mechanism called stimulated emission. The trivalent erbium or neodymium ion is pumped with a high power laser into an excited state where it will stay for a relatively long time (millisecond range), until a signal photon passes and triggers the excited ion to fall back to its ground state energy level, emitting a photon with exact the same wavelength, direction and phase as the incoming signal photon. A lot of effort has been put in incorporating erbium and neodymium in integrated optical devices, in order to compensate for the on chip optical losses or to achieve strong non-linear behavior to facilitate all-optical functions like, for instance, switching or modulation. The efficiency of the rare earth elements depends partly on the excited state lifetime of the ions, which strongly depends on the local environment. A broad range of host materials, like $\mathrm{SiO}_{2}, \mathrm{Al}_{2} \mathrm{O}_{3}$ and $\mathrm{LaF}_{3}$ have proven to be successful for use in optical amplifiers. However, deposition of these glassy and ceramic materials is time consuming and expensive. Furthermore, etching of micron sized waveguide structures into these, often inert, materials is not straightforward and 
expensive as well. The use of low cost photosensitive polymers or sol-gel based materials would enhance the ease of processing and drastically reduce the costs, since the thin films can easily be spin-coated onto a wafer. However, the $\mathrm{CH}$ and $\mathrm{OH}$ bonds that are always present in these materials are strong energy quenchers of the rare earth ions, resulting in very short excited state lifetimes, decreasing the probability to generate stimulated emitted photons. We combined the properties of both the inorganic and organic material systems by synthesizing erbium and neodymium doped $\mathrm{LaF}_{3}$ nanoparticles that can be dispersed in photosensitive polymer and sol-gel solutions. The resulting hybrid materials can be spin-coated onto a sample, followed by a UV-exposure and development step to fabricate optically active multimode and monomode waveguides (2).

\section{EXPERIMENTAL}

Nanoparticle preparation.

Two types of rare earth doped $\mathrm{LaF}_{3}$ nanoparticles have been synthesized, i.e. cyclopentanone-soluble and water-soluble particles for application in photosensitive polymers and tetraethylorthosilicate (TEOS) water based sol-gels, respectively. Since the procedure is more or less similar for both types of particles, only the preparation of the water-soluble particles will be discussed in this section. More information on the preparation of the cyclopentanone-soluble particles can be found in the article of Stouwdam et al. (3).

We dissolved $0.126 \mathrm{~g}$ of $\mathrm{NaF}$ as the fluorine precursor in $35 \mathrm{ml}$ of water. To this solution we added $2.0 \mathrm{~g}$ of citric acid, $\mathrm{HOC}(\mathrm{COOH})\left(\mathrm{CH}_{2} \mathrm{COOH}\right)_{2}$, followed by neutralizing the solution with $\mathrm{NH}_{4} \mathrm{OH}$ until a $\mathrm{pH}$ of 7 and heating it to $75^{\circ} \mathrm{C}$. The molecular structure of citric acid is shown in Figure 1a. In solution, the $\mathrm{OH}$ groups loose the hydrogen and become negatively charged. The citrate molecules will encapsulate the $\mathrm{LaF}_{3}$ particles during growth, determining the final size of the particles and making sure that the particles dissolve well in water.

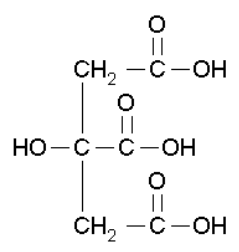

(a)

Citric acid

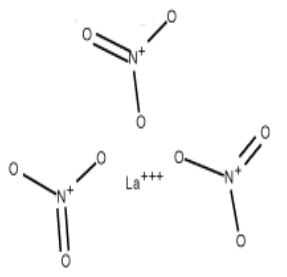

(b) $\mathrm{La}\left(\mathrm{NO}_{3}\right)_{3}$

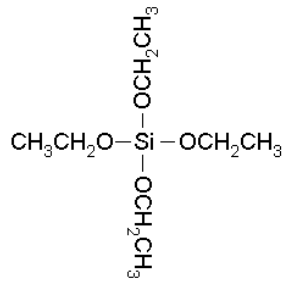

(c)

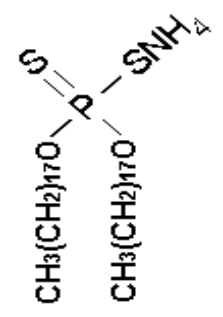

(d)

Dithiophosphate

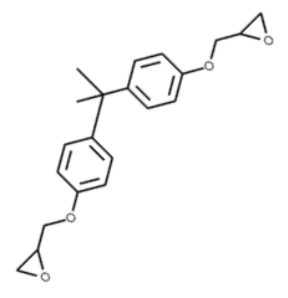

(e) BPA diglycidyl ether

Figure 1: Molecular structures of some of the precursors used in this research.

When the solution reached $75^{\circ} \mathrm{C}$, a $2 \mathrm{ml}$ solution of $0.5473 \mathrm{~g} \mathrm{La}\left(\mathrm{NO}_{3}\right)_{3} \cdot 6 \mathrm{H}_{2} \mathrm{O}$ (Figure $1 \mathrm{~b}$ ) and $0.0288 \mathrm{~g} \mathrm{Er}\left(\mathrm{NO}_{3}\right)_{3} .5 \mathrm{H}_{2} \mathrm{O}$ was added drop wise to serve as the lanthanum and erbium precursors. The ratio between these two precursors determines the final erbium concentration inside the particle, which is 5 atomic percent in this case. In order to synthesize neodymium doped nanoparticles, the erbium nitrate is simply replaced by its neodymium counterpart, $\mathrm{Nd}\left(\mathrm{NO}_{3}\right)_{3} \cdot 6 \mathrm{H}_{2} \mathrm{O}$. The reaction was allowed for two hours after which $100 \mathrm{ml}$ of ethanol was added to precipitate the citrate incorporated $\mathrm{LaF}_{3}: \mathrm{Er}$ 
particles that were formed. Finally, the particles were separated by centrifugation at $3500 \mathrm{rpm}$, washed with ethanol and dried under vacuum. The average diameter of the formed nanoparticles is around $6 \mathrm{~nm}$ as can be seen in Figure 2.

\section{$\underline{\text { Host materials }}$}

As mentioned in the introduction, two types of nanoparticle hosts that can be spin coated are of interest, namely photosensitive polymers and sol-gels. A photosensitive polymer is an interesting material in order to fabricate $\mathrm{LaF}_{3}: \mathrm{Nd}$ doped waveguides in a one step lithography process, since polymers have an optical transmission window around $1330 \mathrm{~nm}$ where the neodymium is active. The sol-gels are more suitable as hosts for the $\mathrm{LaF}_{3}: \mathrm{Er}$ nanoparticles, because the inorganic glass structure of the final film can sustain higher annealing temperatures to remove $\mathrm{OH}$ bonds that cause absorption in the wavelength region of interest $(1530 \mathrm{~nm})$ and quench the excited states of the erbium.

For the photosensitive polymer we used a form of diglycidyl ether of

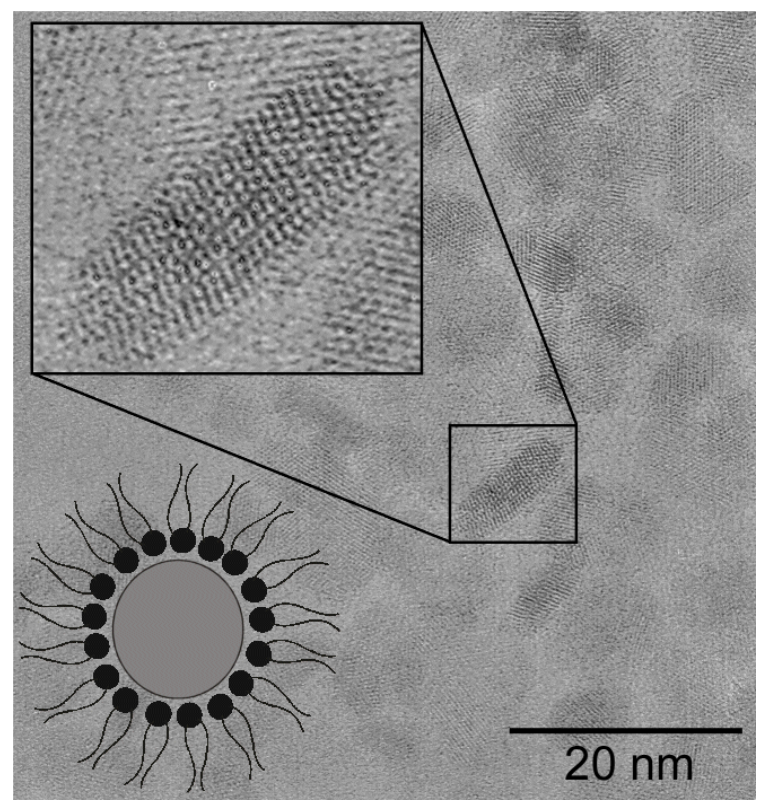

Figure 2: Transmission electron microscope image of $\mathrm{LaF}_{3}$-nanoparticles.

Bisphenol A (BPA) as the base material (Figure 1e), which is an optically clear material that can be solved in cyclopentanone. Precursors come in a wide range of chain lengths, determining the reactivity and viscosity. The chain length should be chosen such that a dry film is formed after spin coating in order to facilitate contact UV exposure through a photo mask. Additionally, a photo-initiator, adhesion promoter and the $\mathrm{LaF}_{3}: \mathrm{Nd}$ nanoparticles are added to the solution. The ammonium di- $n$-octadecyldithiophosphate (Figure 1d) used in the nanoparticle preparation (3) prevents clustering of the nanoparticles. The hydrocarbon tails are extending outward, while the negatively charged sulfur ion adheres to the particle. Figure 2 shows a typical transmission electron microscope (TEM) image of the nanoparticles. In the lower left bottom inset, a schematic representation of a dithiophosphateencapsul-ated nanoparticle is shown. Depending on the solvent concentration and spinning speed, uniform nanoparticle doped films with a thickness ranging from $500 \mathrm{~nm}$ to $5 \mu \mathrm{m}$ can be deposited. A 5-minute baking step at $95^{\circ} \mathrm{C}$ to remove the solvents is followed by a 1 minute UV exposure step in a standard mask aligner through a chrome mask using standard I-line lithography. The acids, that are generated by the photo-initiator during UV

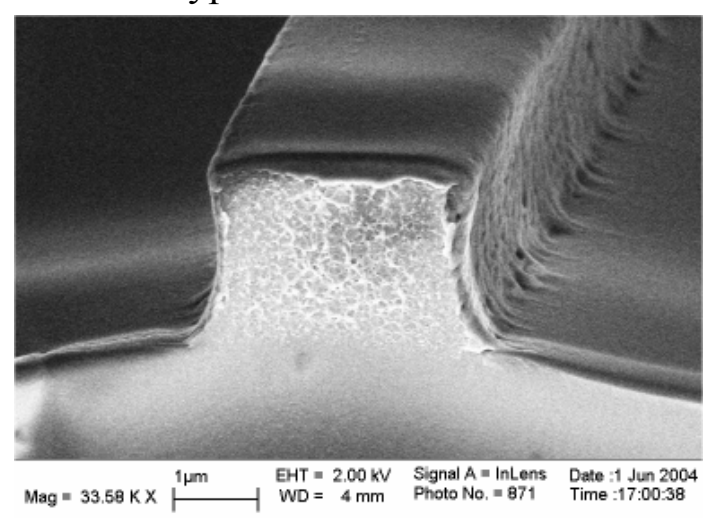

Figure 3: SEM image of a monomode polymer waveguide. 
exposure, open up the epoxy groups of the BPA (Figure 1e) during a 2 minute after exposure bake at $95^{\circ} \mathrm{C}$. During this after exposure bake, the reactive epoxy groups will form a cross-linked network. The unexposed parts of the film can be removed with a standard resist developer (RER600, PGMEA). Figure 3 shows a scanning electron microscope (SEM) image of a monomode optical waveguide.

The inorganic $\mathrm{SiO}_{2}$ host was prepared through the sol-gel method, based on the procedure reported by Xiang et al. (4). Around $80 \mathrm{mg}$ of the citrate incorporated $\mathrm{LaF}_{3}: \mathrm{Er}$ particles (preparation described earlier) were dissolved in $1 \mathrm{ml}$ of water. To this, we added $3 \mathrm{ml}$ of tetraethylorthosilicate (TEOS, Figure 1c) as the precursor for $\mathrm{SiO}_{2}$ and $7.8 \mathrm{ml}$ ethanol. The $\mathrm{pH}$ was brought to 2 by adding a few drops of concentrated $\mathrm{HCl}$. This solution was spin coated onto a silicon wafer yielding uniform films. Two heat treatment steps at $100^{\circ} \mathrm{C}$ and $300^{\circ} \mathrm{C}$ were carried out to form a crack free $\mathrm{SiO}_{2}$ network. A spinning speed of $3600 \mathrm{rpm}$ results in a film thickness of $167 \mathrm{~nm}$ after the two baking steps. Additional annealing for 1.5 hours at $1100^{\circ} \mathrm{C}$ causes further densification of the film, resulting in a thickness of $147 \mathrm{~nm}$. Crack free film stacking has been demonstrated this way up to 6 layers, resulting in $1 \mu \mathrm{m}$ thick films (5).

\section{RAYLEIGH SCATTERING}

It is well known that refractive index disturbances will cause scattering of light. This so called Mie-scattering (in case of spherical shapes) can be treated as Rayleigh scattering in case the size of the spheres is small compared to the wavelength of the incident light $(r<<\lambda)$. The Rayleigh scattering cross section, $\sigma_{\text {Rayl }}$, at wavelength $\lambda$ and particle radius $r$ of a particle with refractive index $n_{p}$, embedded in a host with refractive index $n_{h}$, is given by (6):

$$
\sigma_{\text {Rayl }}=\frac{8}{3}\left(\frac{2 \pi n_{h} r}{\lambda}\right)^{4} \cdot\left(\frac{\left(\frac{n_{p}}{n_{h}}\right)^{2}-1}{\left(\frac{n_{p}}{n_{h}}\right)^{2}+2}\right)^{2} \pi r^{2} \quad\left[\mathrm{~m}^{2}\right]
$$

By multiplication of the scattering cross section with the fill fraction $\eta$ of the nanoparticles and subsequently dividing this by the particle volume, one can obtain the total Rayleigh scattering coefficient (7) in $\mathrm{cm}^{-1}$ and the loss in $\mathrm{dB} / \mathrm{cm}$ (5):

$$
a_{\text {Rayl }}=\frac{3 \eta \sigma_{\text {Rayl }}}{4 \pi r^{3}}\left[\mathrm{~m}^{-1}\right] \quad \alpha_{\text {Rayl }}=\frac{\log (e) \cdot a_{\text {Rayl }}}{10} \quad[\mathrm{~dB} / \mathrm{cm}]
$$

The $\lambda^{-4}$ dependency and the strong dependency on the particle radius of $\sim r^{6}$ can be clearly seen in Figure 4 for $\mathrm{LaF}_{3}$ nanoparticles $\left(n_{p}=1.59\right)$ embedded in a silica host matrix $\left(n_{h}=1.45\right)$ and a BPA based polymer host $\left(n_{h}=1.58\right)$, both having a volume fill fraction of $\eta=0.1$. From Figure 4 it can be concluded that the scattering losses of $\mathrm{LaF}_{3}: \mathrm{Er}$ dispersed in $\mathrm{SiO}_{2}$ are still acceptable in case of our nanoparticles with $r=3 \mathrm{~nm}$. The scattering losses in case of the nanoparticles dispersed in the polymer film can be neglected, since both their refractive indices are matched as can be seen in the top graph of Figure 4. 

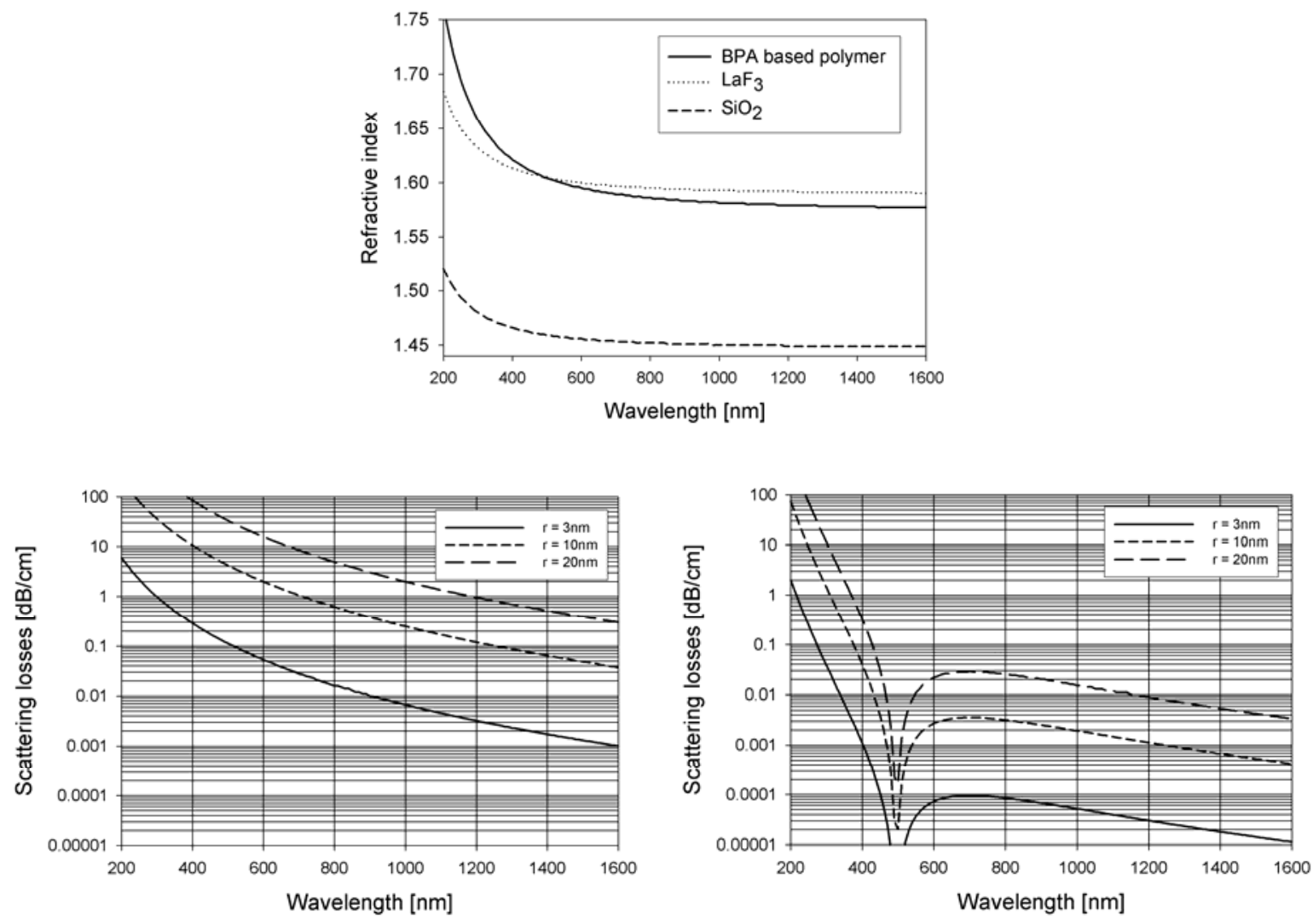

Figure 4: Refractive index versus wavelength for $\mathrm{BPA}, \mathrm{LaF}_{3}$ and $\mathrm{SiO}_{2}$ (top) and the theoretical Rayleigh scattering losses for $\mathrm{LaF}_{3}$ nanoparticles with different sizes in $\mathrm{SiO}_{2}$ (bottom-left) and BPA based polymer (bottom-right), respectively.

\section{LOSS MEASUREMENTS OF POLYMER FILMS}

A dual prism setup has been used to determine the polymer thin film optical losses over a broad wavelength range. A halogen lamp was used as a broad wavelength source, emitting a continuous spectrum ranging from 400-1700nm. The white light from this source was fed into a fiber bundle with a large diameter of $6 \mathrm{~mm}$. At the other end of the fiber bundle the light is focused onto the corner of a 60-30-90 degree prism using a positive lens with a small focal length $(20 \mathrm{~mm})$. The 90 -degree corner of the prism is being pressed onto the sample, creating a thin air gap to facilitate evanescent field coupling into the thin film. Because the wavelengths are supplied over a broad range of angles using the positive lens, the coupling condition [4] is satisfied for all wavelengths.

$$
N_{\text {eff }}=n_{p} \sin \left[\alpha_{p}+\arcsin \frac{\sin \theta}{n_{p}}\right]
$$


Where $N_{\text {eff }}$ is the effective index of a particular optical mode in the thin film, $n_{p}$ is the refractive index of the prism, $\alpha_{p}$ represents the base angle of the prism and $\theta$ is the external angle at which the light enters the prism. After a certain distance $d$, another prism is being pressed onto the sample in order to couple the propagating light out of the film again. The light is then focused onto another fiber bundle and fed into a photo spectrometer (Spectro320 from Instrument Systems). Figure 5 shows a schematic drawing of the measurement setup.

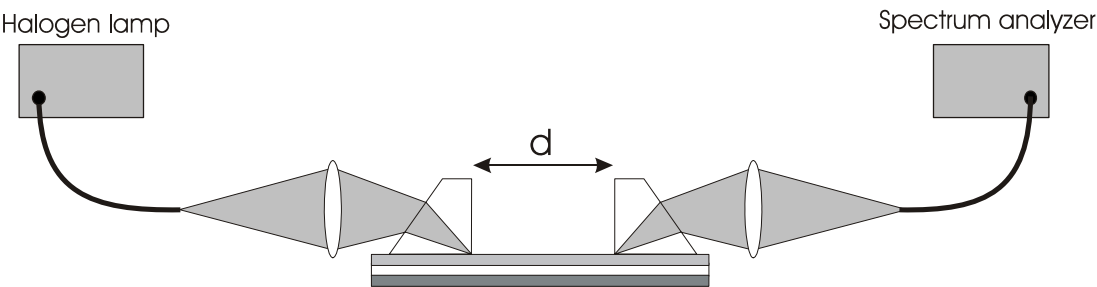

Figure 5: Schematic drawing of the dual prism loss measurement setup.

After each spectral measurement, the transmission spectrum is stored and the outcouple prism is moved with a step $\Delta d$ towards the incouple prism, after which a next transmission spectrum is being recorded. This procedure is repeated several times, until the prisms are in closest proximity to each other. Once a series of spectra has been recorded, the data can be processed to determine the thin film optical losses as function of wavelength. Figure 6 shows an example of this procedure in the wavelength range $1100 \mathrm{~nm}-1300 \mathrm{~nm}$ where absorption peaks due to $\mathrm{CH}$ bonds are located.
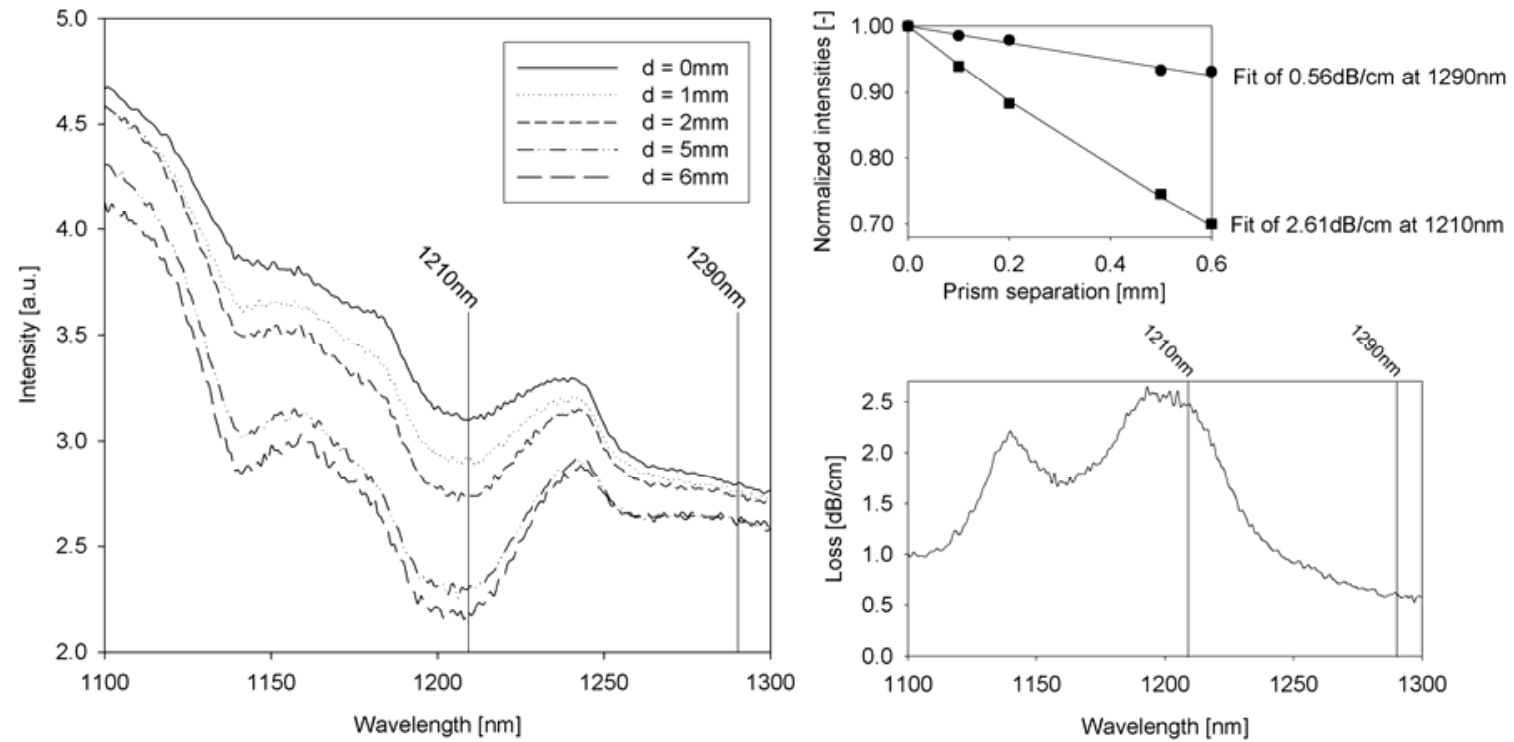

Figure 6: Optical loss calculations using a range of transmission spectra. As an example, the theoretical fits are shown for two wavelengths $(1210 \mathrm{~nm}$ and $1290 \mathrm{~nm})$ around the $3^{\text {rd }}$ overtone absorption band of the $\mathrm{CH}$-bonds that are present in the polymer. 

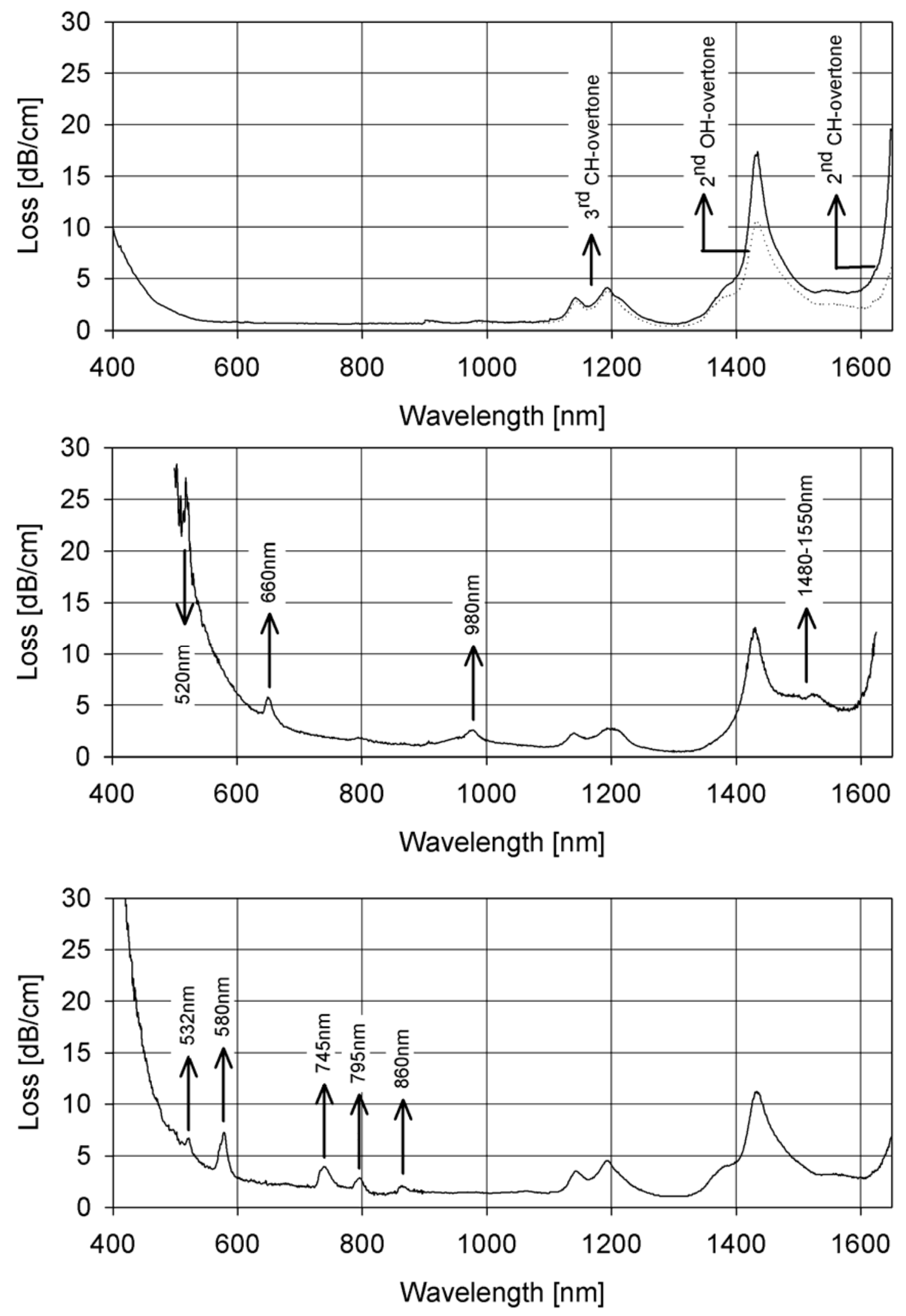

Figure 7: Optical loss spectra of an undoped photosensitive polymer thin film (top), and of the same polymer dispersed with erbium (middle) and neodymium (bottom) doped $\mathrm{LaF}_{3}$ nanoparticles, respectively. 
In Figure 7, the optical losses are shown of an undoped photosensitive polymer thin film (top), and the same polymer dispersed with erbium (middle) and neodymium (bottom) doped $\mathrm{LaF}_{3}$ nanoparticles, respectively.

The exponential loss (8) of the polymer films can be clearly observed at short wavelengths in Figure 7, as well as the $3^{\text {rd }} \mathrm{CH}$-overtones around $1175 \mathrm{~nm}$ and the $2^{\text {nd }} \mathrm{OH}-$ overtone around $1438 \mathrm{~nm}$, in good agreement with the overtones described by Groh (9). In case of the undoped polymer film, the $\mathrm{CH}$ absorption remains constant while the $\mathrm{OH}$ absorption decreases (dotted line), as expected, after a short $100^{\circ} \mathrm{C}$-baking step to remove the absorbed water. Furthermore, the typical absorption lines of the erbium (520nm, $660 \mathrm{~nm}, 980 \mathrm{~nm}$ and $1480-1550 \mathrm{~nm})$ and the neodymium $(532 \mathrm{~nm}, 580 \mathrm{~nm}, 745 \mathrm{~nm}, 795 \mathrm{~nm}$, and $860 \mathrm{~nm}$ ) are clearly shown. The loss due to the erbium and neodymium can be used to determine the rare earth concentration, $N\left(\right.$ in $\mathrm{cm}^{-3}$ ), of the film by dividing the wavelength dependent loss, $a(\lambda)\left(\right.$ in $\mathrm{cm}^{-1}$ ), by the absorption cross section, $\sigma(\lambda)$ (in $\mathrm{cm}^{2}$ ), of the corresponding rare earth ion. Scattering of the nanoparticles $(n=1.59)$ does not cause the increased absorption at shorter wavelengths, since its refractive index is matched by the polymer $(\mathrm{n}=1.58)$, but by $\mathrm{UV}$ absorption of the yellowing ligands, which are attached to the nanoparticles. This is also indicated by the fact that the absorption tail at the short wavelengths has an exponential behavior instead of the $\lambda^{-4}$ behavior in case of Rayleigh scattering.

\section{LIFETIME ENHANCEMENT IN ANNEALED SILICA FILMS}

As mentioned earlier, in the case of erbium, the $\mathrm{CH}$ and $\mathrm{OH}$ bonds that are present in both the polymer and sol-gel based films cause background losses in the wavelength region of interest and the latter is a serious energy quencher of the excited state of the erbium ions. The glassy $\mathrm{SiO}_{2}$ films prepared by the TEOS based sol-gel process can be annealed at high temperatures in order to anneal out the $\mathrm{OH}$ and $\mathrm{CH}$ bonds. Figure 8 shows the erbium decay curves of the $\mathrm{LaF}_{3}: \mathrm{Er}$ doped $\mathrm{SiO}_{2}$ (previously discussed) after annealing for 12 hours at temperatures of $600^{\circ} \mathrm{C}$ and $800^{\circ} \mathrm{C}$, respectively. Furthermore, the decay curves are shown for TEOS based $\mathrm{SiO}_{2}$ films, where the erbium ions were directly incorporated into the $\mathrm{SiO}_{2}$ matrix by adding the $\mathrm{Er}\left(\mathrm{NO}_{3}\right)_{3} .5 \mathrm{H}_{2} \mathrm{O}$ salt to the sol-gel instead of the $\mathrm{LaF}_{3}: \mathrm{Er}$ nanoparticles. The samples were excited with $5 \mathrm{~ns}$ pulses from a Quantel Nd-YAG laser at $488 \mathrm{~nm}$. 


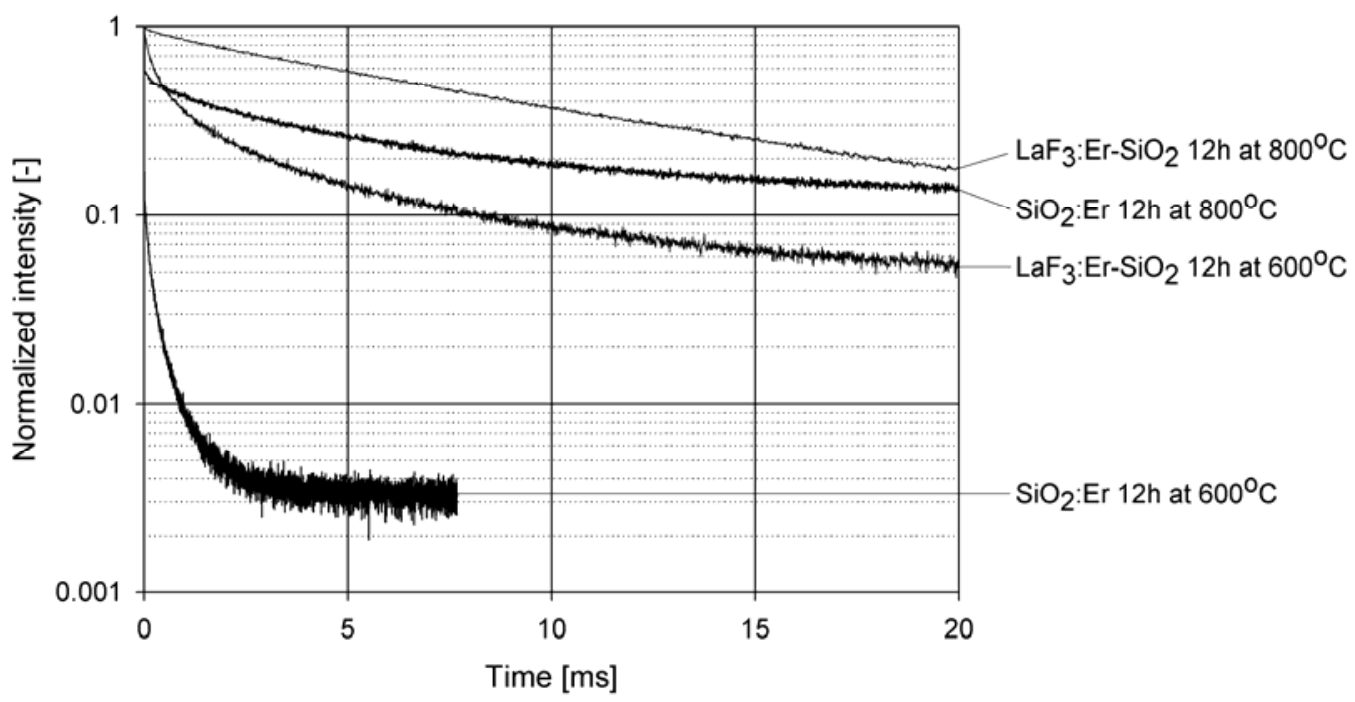

Figure 8: Erbium decay curves of erbium doped TEOS based silica and erbium doped $\mathrm{LaF}_{3}$ nanoparticles dispersed in TEOS based silica, annealed for $12 \mathrm{~h}$ at $600^{\circ} \mathrm{C}$ and $800^{\circ} \mathrm{C}$.

The excited state lifetime of the erbium ions, defined as the time where the emitted photon intensity reaches the $1 / e$ value of the normalized intensity at $t=0 \mathrm{~s}$, can be derived from the decay curves of Figure 8. The fitted results are listed in Table I.

Table I: Lifetime values with the relative percentages of the decay components in brackets.

\begin{tabular}{|c|c|c|c|c|}
\hline \multirow{2}{*}{ Temp } & \multicolumn{2}{|c|}{$\mathrm{LaF}_{3}: \mathrm{Er}_{-} \mathrm{SiO}_{2}$ films } & \multicolumn{2}{c|}{$\mathrm{SiO}_{2}: \mathrm{Er} \mathrm{films}$} \\
\cline { 2 - 5 } & $\tau_{1} \mathrm{~ms}(\%)$ & $\tau_{2} \mathrm{~ms}(\%)$ & $\tau_{1} \mathrm{~ms}(\%)$ & $\tau_{2} \mathrm{~ms}(\%)$ \\
\hline $600{ }^{\circ} \mathrm{C}$ & $7.4(69 \%)$ & $0.9(31 \%)$ & $0.98(35 \%)$ & $0.27(65 \%)$ \\
\hline $800{ }^{\circ} \mathrm{C}$ & $10.9(95 \%)$ & $3.9(5 \%)$ & $6.0(70 \%)$ & $1.2(30 \%)$ \\
\hline
\end{tabular}

For both annealing temperatures it can be seen that the lifetimes are higher for the samples where the erbium is surrounded by the $\mathrm{LaF}_{3}$ matrix. This is because the $\mathrm{LaF}_{3}$ matrix is shielding the erbium from the $\mathrm{OH}$-quenching environment of the $\mathrm{SiO}_{2}$ host. Furthermore, it is clear that the lifetimes for both samples increase at higher annealing temperatures, indicating a reduction in $\mathrm{OH}$ concentration and/or a better crystallinity of the surrounding matrix.

\section{CONCLUSIONS}

Erbium and neodymium doped $\mathrm{LaF}_{3}$ nanoparticles have successfully been synthesized with citrate and dithiophosphate based ligands to make them soluble in water and cyclopentanone, respectively. The rare earth doped nanoparticles were dispersed into a photosensitive (UV-cross linkable) BPA polymer and monomode optical waveguides 
were fabricated using standard I-line lithography. Absorption spectroscopy has been carried out on the undoped and doped polymer thin films, revealing a broad range of material properties, like the presence of $\mathrm{CH}$ bonds, water absorption, nanoparticle/rareearth concentration, the electronic absorption edge at short wavelengths and the excluding of Rayleigh scattering by the nanoparticles.

Furthermore, TEOS based sol-gels have proven to be good hosts for $\mathrm{LaF}_{3}: \mathrm{Er}$ nanoparticles, since they can be annealed at high temperatures to reduce the $\mathrm{OH}$ concentration. The excited state lifetime of the erbium in these samples was increased to $10.9 \mathrm{~ms}$, which is high compared to other erbium doped sol-gel based thin films.

Both the organic and inorganic host materials in combination with the rare-earth doped $\mathrm{LaF}_{3}$ nanoparticles offer the possibility to deposit optically active thin films at low cost. Expensive and time consuming etch processes can be avoided in case of the neodymium doped nanoparticles in combination with the photosensitive polymer using standard I-line lithography. The inorganic sol-gel based films can be used as active cladding materials on top of passive waveguides.

We are currently developing a hybrid photosensitive host material that consists of both silica and hydrocarbon bonds (ceramic/organic) in order to reduce the losses around the $1530 \mathrm{~nm}$ window.

\section{ACKNOWLEDGEMENTS}

The authors would like to thank Remco Nieuwland for preparing the $\mathrm{LaF}_{3}: \mathrm{Nd}$ doped polymer thin films. This research is supported by the Freeband Impulse technology program of the Ministry of Economic Affairs of the Netherlands.

\section{REFERENCES}

1. A. Polman, Physica B, 300, 78-90 (2001).

2. R. Nieuwland, R.Dekker, L.T.H. Hilderink, M.B.J. Diemeer, K. Wörhoff, J.W. Stouwdam, F.C.J.M. van Veggel and A. Driessen, Proceedings of the 2004 Annual Symposium IEEE/LEOS Benelux Chapter, 2-3 December 2004, Ghent University, Belgium, 323-326, ISBN: 9076546061.

3. J.W. Stouwdam and F.C.J.M. van Veggel, Nano Lett., 2(7), 733-737 (2002).

4. Q. Xiang, Y.Y. Zhou, B.S. Ooi, Y.L. Lam, Y.C. Chan and C.H. Kam, Thin Solid Films, 370, 243 (2000).

5. R.Dekker, V. Sudarsan, F.C.J.M. van Veggel, K. Wörhoff and A. Driessen, Proceedings of the 2004 Annual Symposium IEEE/LEOS Benelux Chapter, 2-3 December 2004, Ghent University, Belgium, 295-298, ISBN: 9076546061.

6. A. J. Cox, A. J. DeWeerd, and J. Linden, Am.J.Phys., 70(6), 620-625 (2002).

7. L. H. Slooff, A. v. Blaaderen, A. Polman, G. A. Hebbink, S. I. Klink, F. C. J. M. v. Veggel, D. N. Reinhoudt, and J. W. Hofstraat, Appl. Phys. Rev. 91(7), 3955-3980 (2002).

8. F. Urbach, Phys.Rev., 92, 1324 (1953).

9. W. Groh, Makromol.Chem., 189, 2861-2874 (1988). 